\title{
Spinal Cord Injury Clinical Registries: Improving Care across the SCl Care Continuum by Identifying Knowledge Gaps
}

\author{
Marcel F. Dvorak, Christiana L. Cheng, ${ }^{2}$ Nader Fallah, Argelio Santos, Derek Atkins, \\ Suzanne Humphreys, ${ }^{2}$ Carly S. Rivers, 2 Barry A.B. White, Chester Ho, Henry Ahn, \\ Brian K. Kwon, ${ }^{1}$ Sean Christie, and Vanessa K. Noonan ${ }^{6}$
}

\begin{abstract}
Timely access and ongoing delivery of care and therapeutic interventions is needed to maximize recovery and function after traumatic spinal cord injury (tSCI). To ensure these decisions are evidence-based, access to consistent, reliable, and valid sources of clinical data is required. The Access to Care and Timing Model used data from the Rick Hansen SCI Registry (RHSCIR) to generate a simulation of healthcare delivery for persons after tSCI and to test scenarios aimed at improving outcomes and reducing the economic burden of SCI. Through model development, we identified knowledge gaps and challenges in the literature and current health outcomes data collection throughout the continuum of SCI care. The objectives of this article were to describe these gaps and to provide recommendations for bridging them. Accurate information on injury severity after tSCI was hindered by difficulties in conducting neurological assessments and classifications of SCI (e.g., timing), variations in reporting, and the lack of a validated SCI-specific measure of associated injuries. There was also limited availability of reliable data on patient factors such as multi-morbidity and patient-reported measures. Knowledge gaps related to structures (e.g., protocols) and processes (e.g., costs) at each phase of care have prevented comprehensive evaluation of system performance. Addressing these knowledge gaps will enhance comparative and cost-effectiveness evaluations to inform decision-making and standards of care. Recommendations to do so were: standardize data element collection and facilitate database linkages, validate and adopt more outcome measures for SCI, and increase opportunities for collaborations with stakeholders from diverse backgrounds.
\end{abstract}

Keywords: clinical registry; data quality; healthcare system; knowledge gaps; spinal cord injury

\section{Introduction}

$\mathbf{T}$ HE HEALTHCARE SYSTEM aims to optimize patient outcomes, such as neurological recovery and health status, and ensure patients can return to full participation in their communities after sustaining a traumatic spinal cord injury (tSCI). Outcomes are influenced by myriad injury-, patient-, and system-related factors that include but are not limited to severity of injury, patient-specific variables, geography, available healthcare resources, organizational structures, the environment in which care is provided, as well as the staff providing that care. ${ }^{1-3}$ Delivery of care is time-sensitive and must start immediately following injury to the spinal cord and continue into the community, to make sure patients have access to therapeutic interventions that maximize recovery and function. These efforts require access to consistent, reliable, and valid sources of clinical data to ensure decisions are evidence-based.

Prospective clinical registries can power these efforts by collecting data on injury-, patient-, and system-related factors to provide measurements on patient-centered outcomes, cost, safety, and efficacy that are needed for clinical and cost-effectiveness

\footnotetext{
${ }^{1}$ Department of Orthopaedics, ${ }^{3}$ Operations and Logistics Division, Sauder School of Business, University of British Columbia, Vancouver, British Columbia, Canada.

${ }^{2}$ Rick Hansen Institute, Vancouver, British Columbia, Canada.

${ }^{4}$ Division of Physical Medicine and Rehabilitation, Department of Clinical Neurosciences, University of Calgary, Calgary, Alberta, Canada.

${ }^{5}$ University of Toronto Spine Program, Toronto, Ontario, Canada.

${ }^{6}$ Research Division of Neurosurgery, Dalhousie University, Halifax, Nova Scotia, Canada.

(C) Marcel F. Dvorak et al., 2017; Published by Mary Ann Liebert, Inc. This Open Access article is distributed under the terms of the Creative Commons Attribution Noncommercial License (http://creativecommons.org/licenses/by-nc/4.0/), which permits any noncommercial use, distribution, and reproduction in any medium, provided the original author(s) and the source are credited.
} 
research and quality improvement effort. In SCI, at least 13 spine registries exist internationally. ${ }^{4}$ One of these, the Rick Hansen SCI Registry (RHSCIR) established in 2004, is a longitudinal observational registry with a priori research questions that collects demographic and clinical data on patients with tSCI as they transition from the pre-hospital phase to acute, rehabilitation, and community setting from $31 \mathrm{SCI}$ facilities across Canada. ${ }^{5}$ The registry has been providing clinical information to help inform clinicians of beneficial interventions and encourage evidence-based practices. To further inform clinicians and policymakers in making evidencebased decisions about the timing, location, and appropriateness of care delivery, data collected through the RHSCIR was used to construct a healthcare delivery simulation model of the provision of pre-hospital, acute, and rehabilitation services for persons with tSCI. This model, the Access to Care and Timing (ACT) Model V1.0, was developed to test policies aimed to improve healthcare outcomes and reduce the economic burden of SCI by improving timely access to specialized care. ${ }^{2,6}$ However, as the strength and value of registries is confined by the quality and type of data being collected, the impact of these limitations on research and care became apparent during the development of the ACT Model.

The model was part of the ACT project that aimed to model patient flow following tSCI to better understand how injury-, patient-, and system-related factors affect outcomes. The project has applied the knowledge creation cycle component of the "Knowledge-to-Action Process" (Fig. 1) developed by Graham and colleagues. "Knowledge inquiry" was initiated by a series of stakeholder meetings with clinicians, researchers, administrators, policymakers, and persons with SCI from across Canada to identify important policies related to $\mathrm{tSCI}$ care delivery ${ }^{2}$ as mentioned and formed the foci for the simulation model of the tSCI care continuum. In addition to using the RHSCIR as a data source, we also relied on clinical experts to fully develop process maps that describe the patient flow, resource availability, and utilization of the various RHSCIR acute and rehabilitation SCI facilities. In areas where data were not available or quality was poor, we supplemented the published literature with opinions of subject matter experts ("knowledge synthesis"). The resulting ACT Model was to serve as a tool for presenting the knowledge gained from prospective observational registry data collection in a usable format to support decision-making using this available evidence ("knowledge tools/products"). ${ }^{7}$ The output from the knowledge creation cycle has provided the basis for understanding the continuum of healthcare delivery for SCI in Canada and has been presented in this focus issue. ${ }^{8}$ It has also stimulated further knowledge inquiry that stemmed from the challenges encountered during model development in terms of data-related issues in the literature and fragmentation along the care continuum.

The objectives of this article are to: 1) describe the knowledge gaps in the literature throughout the continuum of SCI care that were identified during the evolution of the ACT project, and 2) provide recommendations for bridging some of these gaps. Gaps in knowledge were described in terms of injury, patient factors, and trauma system (structure and process), as each of these components must be understood to provide quality care. ${ }^{9}$ This effort focuses on the use of SCI registries in collecting specific patient-level data, integrating with other data sources, and utilizing it to accelerate improvements in care through the Knowledge-to-Action Process. Beyond simply using prospectively collected observational data to fill gaps in knowledge, we would hope that thoughtful analyses will

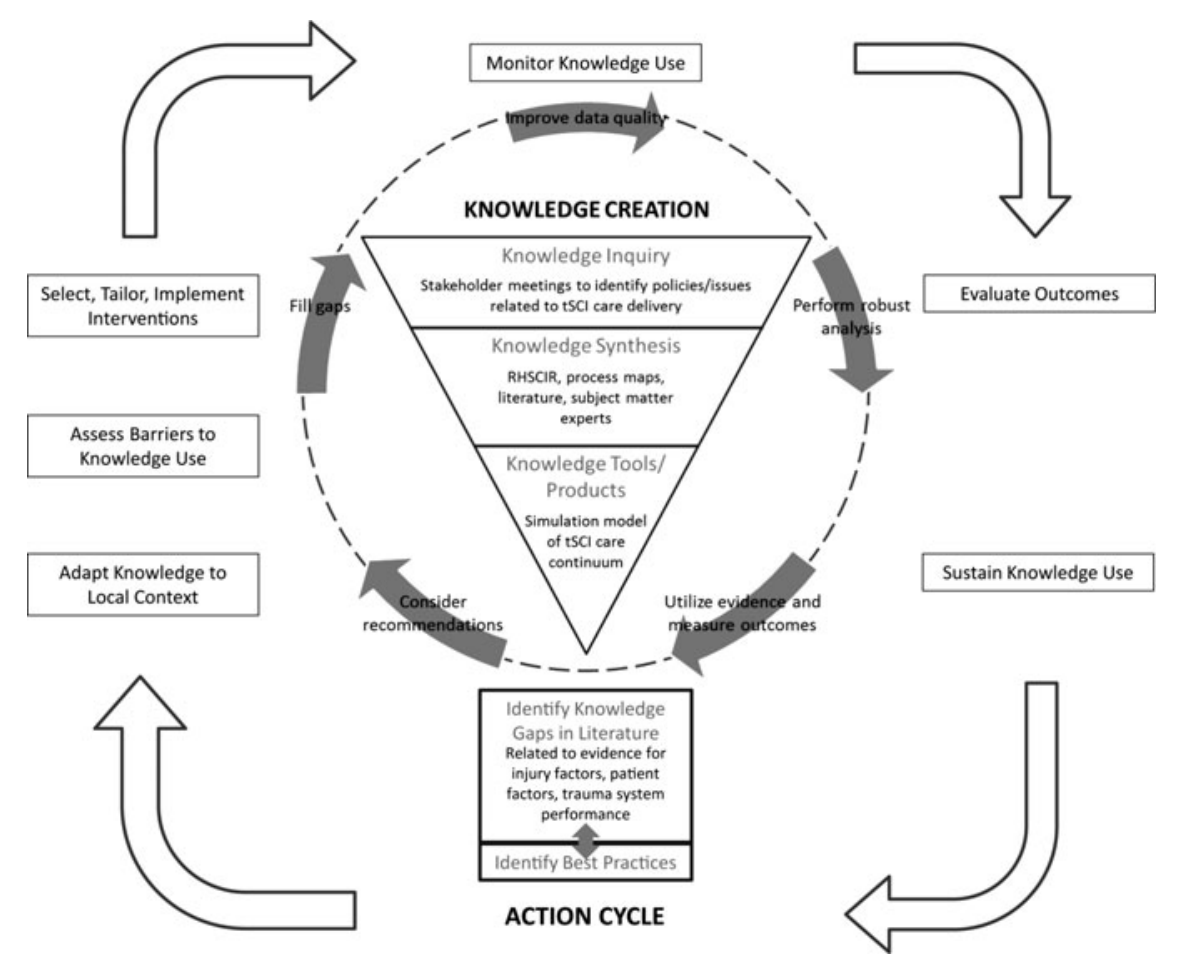

FIG. 1. Modified Knowledge-to-Action Cycle used in the ACT project (adapted from Lost in knowledge translation: Time for a map? Graham ID, et al. Journal of Continuing Education in the Health Professions, 26(1). Copyright @2006. The Alliance for Continuing Education in the Health Professions, the Association for Hospital Medical Education, and the Society for Academic Continuing Medical Education. Used with permission.). ACT, Access to Care and Timing; RHSCIR, Rick Hansen Spinal Cord Injury Registry; tSCI, traumatic spinal cord injury. 
also facilitate the implementation of best practices and novel therapeutic interventions that can improve care across the SCI care continuum.

\section{Injury Factors}

The need for data standards to improve data quality and enable the comparison and/or aggregation of data among studies has been described as a requirement to advance research and improve clinical care in both the fields of $\mathrm{SCI}^{10}$ and traumatic brain injury (TBI). ${ }^{11}$ Gaps in standardizing data elements for injury have become apparent in SCI research in our attempts to develop a robust ACT simulation model for tSCI care. Gaps pertaining to neurological assessment and classification of SCI, variations in reporting, valid assessments of associated injuries, as well as population estimates of the incidence, prevalence, and mortality were identified.

\section{Neurological assessment and classification of SCl}

A requirement for both SCI clinical practice and research is an objective and measurable motor and sensory examination to determine the severity and location of the cord injury. We identified challenges in obtaining standardized neurological assessments performed in a timely fashion, by trained clinicians, and repeated as an integral component of the processes of care. The International Standards for Neurological Classification of SCI (ISNCSCI) are the current standards recommended worldwide to describe and classify the severity of SCI. ${ }^{12}$ However, the assessment is time-consuming and requires proper training, as well as a responsive patient without which an incomplete or imprecise classification can be the result. Precise information on injury severity is important not only for guiding treatment options and prognosis, but it should also be used to stratify participants and evaluate therapeutic efficacy within future clinical intervention trials. ${ }^{13-17}$ Beyond simply reporting on the baseline ISNCSCI evaluation, it has become apparent that precisely defining the timing of that baseline neurological examination is critical in avoiding biases. SCI therapeutic trials would benefit from a standard definition of the timing of baseline neurological evaluation and investigations in relation to the time that the injury occurred. Mandated reporting of the time from injury to baseline neurological examination would minimize the risk of bias or at least aid in its identification.

\section{Variation in reporting injury}

One of the major research gaps identified recently is our imprecise knowledge regarding the extent to which certain profoundly important predictors of injury severity influence the neurological and clinical outcomes of individuals with SCI. There is no agreement on the standardized requirements for reporting on the composition of study cohorts in therapeutic or even observational clinical trials. Interactions between injury severity and anatomical location, ${ }^{16}$ as well as a lack of reporting of the skeletal injury pattern while consistently reporting less impactful features such as mechanism of injury, create imbalances within study cohorts that cannot be fully appreciated by clinical investigators. ${ }^{18}$ There is a need to develop consistent guidelines on the clinical reporting of study cohorts, and ideally to make this patient-level data available to other investigators for broader meta-analyses. ${ }^{19,20}$

\section{Assessment of associated injuries}

There is yet a validated SCI-specific measure to capture the extent of injury, other than SCI, to all body systems. In the field of
SCI research, Glasgow Coma Scale (GCS) ${ }^{21}$ and Injury Severity Score (ISS) ${ }^{22}$ are the measures of associated injuries most commonly used to predict patient short-term outcomes such as in-hospital complications and mortality. ${ }^{23,24}$ However, these measures have not been validated in persons with SCI. Further, the ISS calculation includes the spine region, which is usually captured in a separate variable using ISNCSCI (i.e., American Spinal Injury Association [ASIA] Impairment Scale score). ${ }^{12}$ This can cause potential problems of co-linearity with the ASIA Impairment Scale score when included together in a prediction model affecting the accuracy of conclusions derived. Establishing the validity of ISS in persons with SCI or developing an SCI-specific associated injury measure is needed to appropriately account for the influence of these other injuries on the patients' recovery trajectories.

\section{Population-based estimates of incidence, prevalence, and mortality}

Accurate data on the incidence of acute traumatic and nontraumatic SCI is limited both in the literature and the RHSCIR, thus using RHSCIR data in the ACT Model for creation of simulated patients is an estimate that is not entirely population-based. tSCIdedicated national registries such as the RHSCIR and National Spinal Cord Injury Statistical Center (NSCISC) ${ }^{25}$ prospectively capture data on only a proportion of the total number of individuals who suffer an acute SCI because those admitted to nonparticipating facilities are not included. Lack of resources and an appropriate central population-based data repository are challenges faced by many non-participating facilities in reporting new injuries to the participating facilities.

Most literature citing incidence resorts to a retrospective review of the hospital or non-SCI specific registry records using administrative codes (i.e., ICD codes), but this limits their sample population to those who have survived the initial injury, ${ }^{26,27}$ as individuals who die before reaching a hospital and receiving a diagnosis are usually not accounted for in hospital records. Such methodology also poses a risk of misclassifying tSCI when conducted using ICD codes alone. ${ }^{28-30}$ Another limitation of the retrospective approach is that the data fields are limited to the information collected at the time and may limit the comparability with other datasets. There are also variations in the literature on the definition of tSCI, the administrative codes used, and the incidence reporting (initial ${ }^{31}$ vs. discharge ${ }^{26,27}$ ), making incidence comparison across studies difficult.

In addition to reflecting an accurate situation in tSCI incidence, pre-hospital mortality data are also important for identifying opportunities to improve care and survival. However, Canadian data on mortality are difficult to access due to privacy and provincial and federal jurisdictional issues resulting in little accessible information on mortality from SCI at the scene of injury or in the prehospital phase. Information related to the demographics, etiology of injury, and mortality profiles of those who die at the scene of a severe SCI are critical for guiding appropriate and effective prehospital management and prevention strategies.

Addressing these challenges in obtaining a complete and accurate picture of incidence and epidemiology of SCI would help researchers and policymakers understand SCI care provisions in the context of the local incidence rates. It will be imperative to ensure that all registries align with the SCI Common Data Elements (CDEs) recently developed by the National Institute of Neurological Disorders and Stroke (NINDS) ${ }^{10}$ for standardized data collection, and that they feed into the global living repository 
of SCI incidence and prevalence created by the International Spinal Cord Society (ISCoS). ${ }^{32}$

\section{Patient Factors}

The ACT Model covers the care continuum from pre-hospital phase to community reintegration, and one of the most significant gaps in knowledge identified that spanned multiple phases of care was the limited availability of reliable data on patient factors such as multi-morbidity (i.e., comorbidities, secondary complications, and adverse events) and patient-reported measures. Comorbidities refer to the pre-injury status, secondary complications arise as a consequence of SCI, and adverse events are caused by medical errors. Data on multi-morbidity are collected in the RHSCIR using hospital administrative codes and their inadequacy for SCI research are described below.

\section{Comorbidities, complications, adverse events}

Pre-injury comorbidities influence not only the initial severity of injury, but also the potential for neurological recovery and propensity to develop complications and adverse events consequent to the SCI and to its subsequent treatment. Documenting baseline preinjury comorbidities is critical but the identification and recording of morbidity varies across the healthcare continuum and across centers in different regions; this effectively precludes the determination of any interactions between comorbidities and complications or adverse events.

Patients who experience a complication or an adverse event during the pre-hospital or acute phase of care will likely be predisposed to further similar or associated events during rehabilitation and subsequent community living. For example, the presence of a preinjury chronic obstructive lung disease, or the diagnosis of an aspiration pneumonia in the first days following injury, may very well influence the lifelong risks for further respiratory complications, not just during in-hospital rehabilitation but well beyond discharge into the community. Tracking patients along this continuum to define this increased risk has not occurred as there is no standard method of measuring and documenting comorbidities that is reliable and validated for the SCI population. Further, most reports of complications occur within the confines of either acute care or rehabilitation or community living and do not cross these boundaries.

In creating the ACT Model, due to the inconsistent collection of complications and adverse events across centers based on administrative data, we had to resort to relatively poor quality evidence in the literature to attempt to predict the risks for developing many of these SCI-associated complications and adverse events. ${ }^{33}$ The literature available on complications in the SCI population has substantial limitations as most data rely on retrospective queries of hospital databases using ICD codes. These codes have been shown to grossly underestimate the incidence and impact of morbidities due to the fact that data collection is subject to coding errors and usually captures only conditions that impact the patient's hospital length of stay (LOS). ${ }^{34,35}$ Further, the ICD-based coding does not distinguish well between pre-injury comorbidities, complications that are consequent of SCI, and adverse events caused by medical errors, from the perspective of SCI pathogenesis. Rather, these codes focus on the perspective of when these diagnoses were made in relation to the time spent in the admitting hospital.

Without reliable data on these comorbidities, complications, and adverse events, it is not only challenging to define their relationship to healthcare costs and patient-related outcomes, but also to establish appropriate strategies to reduce their burden. The validated
Spine Adverse Events Severity system (SAVES), ${ }^{34,36}$ which prospectively captures adverse events at some of the RHSCIR acute facilities, should be implemented throughout the SCI continuum. In addition, freely available resources such as Spinal Cord Injury Research Evidence (SCIRE) ${ }^{37}$ that assist clinicians in standardizing their assessments regarding complications should be made available as a part of the solution to closing this gap in knowledge.

\section{Patient-reported measures}

Even though it has been suggested that information from patientreported measures be regarded as a "vital sign" 38 and represent the "patient voice," there continues to be challenges in implementing these measures into care. Patient-reported measures include both patient-reported outcome measures (PROMs), which ask about physical and mental health, and patient-reported experience measures (PREMs), which assess patients' experience with receiving care (e.g., accessibility of services, timeliness, and coordination of care). ${ }^{39}$ Quantitative PROMs and PREMs are still limited, as adoption of these measures in the hospital setting is not common. ${ }^{38}$ In the community setting, most studies employ PROMs when determining the prevalence of health conditions, which could be subject to recall bias and imprecise reporting as some definitions can be confusing. For instance, bladder dysfunction in the literature is expressed in various terms, including "bladder dysfunction," "micturition failure," and "bladder leakage."40-43 In addition, there is a need to measure the impact of the health condition on daily activities as well as on social participation such as return to work. These types of measures are part of the RHSCIR Community Follow-up Questionnaire, ${ }^{44}$ which currently requires patient consent as a research study, but collection of these data should be mandated as a requirement of care under the healthcare provider in the community to support patient-centered care.

\section{Trauma System Performance}

Trauma system performance must consider both the structure and process of each care phase, as well as the entire care continuum as a whole. Structure refers to the characteristics of healthcare delivery such as protocols and guidelines, capacity to collect longitudinal data, and to integrate with other phases in the care continuum. The data quality in clinical registries like the RHSCIR can be impacted by structure-related gaps and so can the quality of care as explained below.

Process refers to the delivery of healthcare as well as the effort to measure the delivery efficiency, which might involve the collection and reporting of data on LOS and cost. The level of care and its respective expenses within a patient's LOS can vary, but this information is not captured in most registries as some hospitals in Canada do not record these cost details at patient level. These process- and structure-related gaps have prevented comprehensive evaluation of trauma system performance and definition of criteria for a center of excellence.

\section{Pre-hospital protocol}

Detailed process mapping of the pre-hospital phase from participating RHSCIR facilities during the development of the ACT Model revealed that there is ambiguity in relation to the triaging decisions and admission protocols. This is due to variation in pre-hospital structure/jurisdiction ${ }^{2}$ and also the uncertainty in the degree to which the actual practice adheres to the triaging protocol. Considerable evidence now supports recommendations for early or direct transport 
to SCI specialty centers to reduce length of hospital stay and complication burden. ${ }^{45,46}$ Therefore, extending the process mapping to multiple healthcare regions to determine the actual triaging process would be critical for clinicians and policymakers to identify relevant strategies for improving timing and access to specialized care.

\section{Longitudinal data}

Unlike the available data on acute and rehabilitation phases in the RHSCIR, detailed information on community care and services is not included in the RHSCIR. This prevented us from creating a comprehensive modeling of the patient flow in the community in the current ACT Model. Instead, the model describes the community phase in terms of a simplified health progression model of long-term healthcare costs and patient outcomes such as quality of life. Data for this model were obtained from the RHSCIR Community Follow-up Questionnaire that is collected for participants who provide consent to the collection of an Expanded SCI Dataset. It captures participant-reported data on life satisfaction, secondary complications and comorbidities, health status, and environmental barriers at 1,2, and 5 years post-initial discharge and every 5 years henceforth. ${ }^{44}$ However, it does not collect detailed information on healthcare service utilization or detailed information on areas such as social participation. This long-term information is valuable in giving newly injured patients realistic expectation. The information can also assist clinicians and policymakers in making decisions regarding resource allocation for community services and supports.

Integrated actions with community clinicians and organizations such as SCI Canada and their provincial organizations are in progress to facilitate community-based longitudinal research efforts by leveraging their network of individuals with SCI. This will facilitate the collection of detailed information in the community. Future work must consider how best to engage persons with SCI in entering their own data using the advances in technology to ensure these data ultimately result in better outcomes for those living with SCI.

\section{Data integration}

Although the promise of "big data" is appealing, the reality of linking between datasets is complex. Efforts are underway to link the RHSCIR and provincial population-based datasets that encompass administrative health services records of the provincial population, but the political and technical challenges in the data request process impose myriad delays and complexities in doing so. Most critical is linking the patient who progresses from one phase of care to the next across the silos of data collection by ambulance and paramedic services, acute and rehabilitation inpatient services, and the aggregation of data reflecting utilization of health resources once the patient returns to the community.

\section{Length of stay}

In Canada, data on facility LOS is submitted to the Canadian Institute for Health Information (CIHI), but it is exceedingly difficult to report on LOS spent in an episode of care either in the acute or rehabilitation phase, or total system LOS..$^{47}$ Definitions of LOS, alternate levels of care (ALC), readiness for rehabilitation, and readiness for discharge are not standardized. As a result, acute care hospitals that do not have direct or timely access to inpatient rehabilitation facilities can "game" the system by discharging patients early to other facilities including community hospitals and long-term care facilities to wait for admission to inpatient rehabilitation. This creates the appearance of shorter acute LOS while truly extending the patients' actual time from injury to reintegration into the community. It also potentially puts patients with SCI at risk by having them wait in facilities that may not have the expertise to provide the specialized care that they require.

We have also identified substantial ambiguity regarding the definitions of clinician-recommended discharge destinations suitable for patients post-acute and/or post-rehabilitation, which might be attributed to lack of standardized discharge planning and processes. A decreasing trend of LOS has been observed in the RHSCIR data and reported in Canada ${ }^{48}$ and the United States, ${ }^{49,50}$ and whether it reflects an actual improvement in efficiency or practice or simply identifies early discharge to other facilities while patients wait for rehabilitation is debatable. The problem of nonideal discharge destinations will be exacerbated with the aging population as described by Ahn and associates in this focus issue. ${ }^{51}$ Further, LOS may change due to the changing demographics of tSCI over the next 30 years, leading to changes in the cost of care.

\section{Costs of care and the economics of SCI}

As the costs of healthcare rise in Canada, more emphasis is being placed on ensuring appropriateness of care and tracking the financial resources spent on various health conditions. Currently, studies on the direct and indirect costs of SCI and the incremental costs of complications are limited. ${ }^{52-54}$ The economic impact of SCI from inpatient hospital stay is based on estimates, as most studies use data from retrospectively auditing hospital billing databases, which may not capture the comprehensive cost information on a patient level. ${ }^{55-57}$ Even less is known about the economic impact of SCI in the community, for which linking between registry data with the Discharge Abstract Database (DAD) and other clinical databases would be required to track the healthcare utilization by those living in the community with SCI. This is not done regularly in any health authorities or provinces that we are aware of and the data are definitely not centralized at this time.

The lack of detailed measures and access to economic data has made it challenging to collect data on the indirect cost of SCI resulting from temporary or permanent disability, loss of employment and reduced productivity at work, as well as unpaid care given by family members or caregivers. ${ }^{58}$ At a recent ACT Workshop ${ }^{59}$ with national stakeholders in the SCI field (e.g., clinicians, policymakers, researchers, and persons with SCI), a key recommendation emerged for national research efforts to determine the immediate and lifetime costs of care and economic impact of SCI to guide policy and practice changes. ${ }^{60}$ In response to this recommendation, an article in this focus issue by White and colleagues presented a case series analysis exploring the direct hospital costs attributed to hospital-acquired pressure ulcers and urinary tract infections. ${ }^{61}$ Further work is also needed to determine which measures have strong psychometric properties to assess health preferences for individuals living with SCI to calculate health utilities and conduct comparative economic analysis.

\section{Definition of center of excellence}

Although we have performed comparative analyses related to structure and process of care in SCI centers across Canada presented in this focus issue article by Noonan and associates, ${ }^{62}$ the recommended attributes and criteria for defining these SCI centers of excellence are still unclear. It would appear from our work and that of others that some of the important structure and process indicators are the transfer of spinal injury patients to an acute SCI center, availability of spinal surgery 24/7; availability of a spine/neuro-specific 


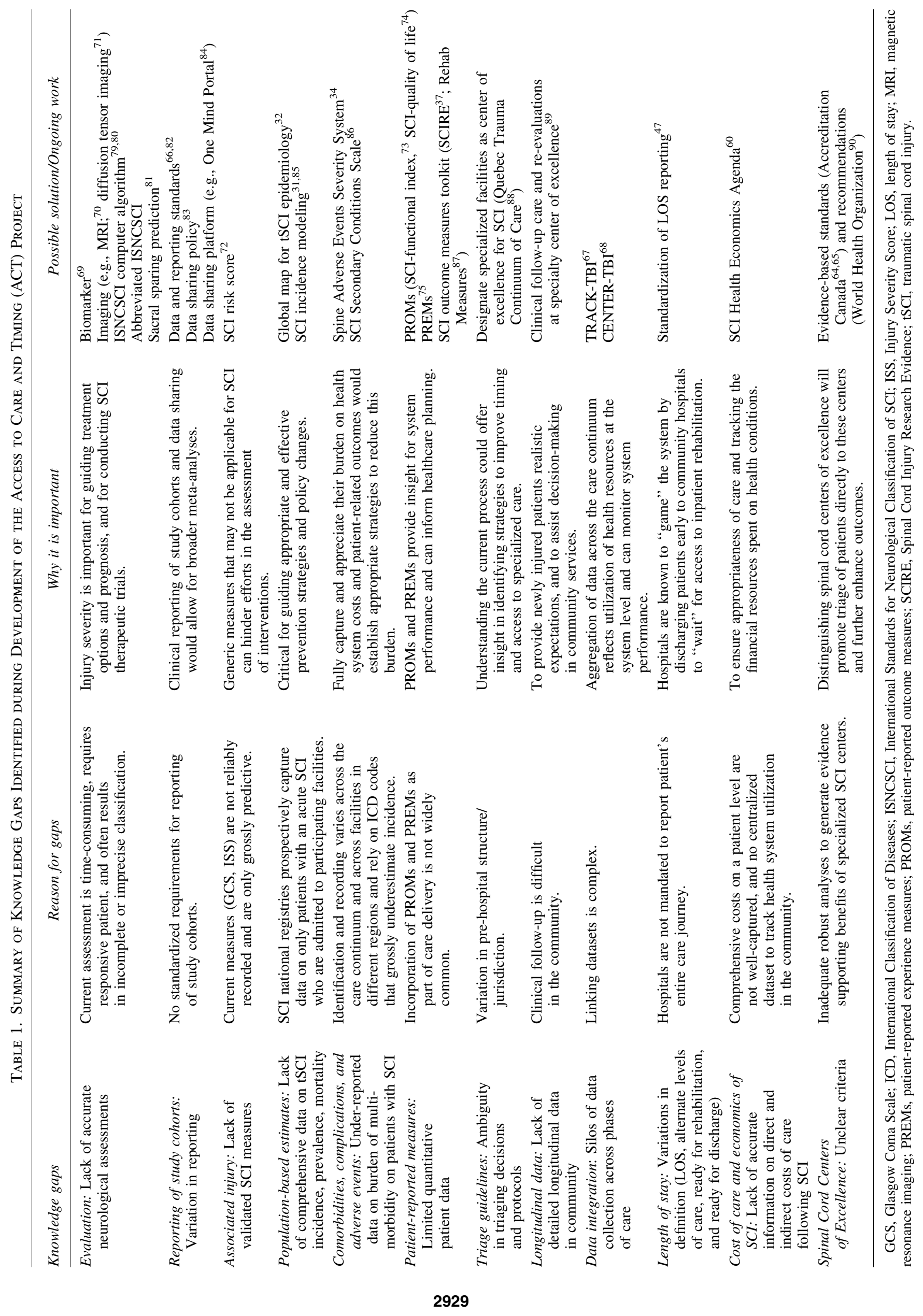


intensive care unit, time from injury to surgery, availability of a specialized SCI rehabilitation team for consultation, and continuity of care ${ }^{62,63}$ More importantly, to define the criteria for a SCI center of excellence, we would need accurate data on both the patients treated at specialized centers and those treated at non-specialized centers to compare outcomes. It is also important to determine the volume of patients with an acute SCI required for a SCI center to maintain its expertise. There are now both SCI acute and rehabilitation accreditation for SCI centers in Canada which might facilitate future development of criteria for SCI centers of excellence. ${ }^{64,65}$

\section{Future Recommendations}

This article has highlighted some gaps in knowledge identified through the development of the ACT Model and preparation of this focus issue. These gaps included a lack of objective neurological assessment and SCI-specific injury measure, incomprehensive data on SCI incidence, incomplete data on complications, patientreported measures and costs throughout the care continuum, and non-standardized reporting of LOS and of study cohorts (Table 1). These gaps have prevented us and others from performing the robust analyses needed to generate evidence supporting benefits of treatment provided during inpatient hospitalization, evaluating trauma system performance, or defining the criteria for specialized SCI centers. Fortunately, there is ongoing work to address these gaps, a subset of which is listed in Table 1. There are also many potential specific recommendations for these gaps but they would all benefit from three high-level recommendations.

1. Implementation of standardized data element collection ${ }^{66}$ and collaborations to link databases from multiple facilities or registries to obtain a comprehensive dataset spanning the entire care continuum $^{67,68}$ that contains information relevant to people living with SCI. Using the same core data elements across the phases of care and between facilities would not only enable researchers and clinicians to conduct research, allowing appropriate benchmarking of performance to support quality improvement efforts, but most importantly would also provide information that can improve the lives of those living with SCI.

2. More outcome measures should be validated for use in SCI to ensure accurate collection of information, prediction of patient's recovery trajectory, and assessment of interventions, ${ }^{69-72}$ after which the validated measures should be adopted. Patientreported measures ${ }^{73-75}$ need to become an integral part of clinical decision-making and healthcare planning and not just for research purposes because these measures are especially important in addressing specific outcomes that are best to be directly reported by patients and in facilitating longitudinal outcome measurements that are currently lacking.

3. Opportunities for international collaboration, such as the PRAXIS Model, ${ }^{76,77}$ with stakeholders from all phases of care and diverse backgrounds should be continuously made available for sharing and coordinating resources in advancing SCI research and care. These efforts would be accelerated by aligning and learning from other fields including TBI; many of the gaps and recommendations outlined in this article are similar to those tackled by key TBI initiatives in developing evidence to support policy and practice for optimizing care in TBI. ${ }^{11,78}$

This article focused on tSCI as this was the target population for the ACT Model; however, it is important to acknowledge that there is a repeated recommendation to include non-traumatic SCI pop- ulations in future research. ${ }^{59}$ Given that healthcare systems and challenges of care provision share some similarities between traumatic and non-traumatic SCI, addressing the gaps faced by tSCI would be valuable not only to optimize care for individuals with tSCI, but it would also inform the research and care improvement endeavors for those suffering from non-traumatic SCI.

\section{Conclusion}

The ACT Model was developed as a tool to assist policymakers and stakeholders to make evidence-based decisions. Through the development of this model, we have increased our understanding of the process of healthcare delivery for tSCI in Canada as well as identified gaps and challenges that exist in current data collection preventing generation of evidence. Addressing these gaps will enhance the comparative effectiveness and cost-effectiveness evaluations that are needed to inform decision-making and standards of care for optimizing the access and timing to specialized services leading to improved patient outcomes and reduced system costs. New knowledge created in this second round will be integrated into the ACT Model to further enhance this tool and provide a better understanding of the ideal attributes of care delivery for persons living with SCI.

\section{Acknowledgments}

The authors thank the Canadian Institutes for Health Research (CIHR) and the Ontario Neurotrauma Foundation (ONF) for their financial support for the ACT Workshop; Elaine Chan and Sophia Park for research assistance; the Rick Hansen Institute RHSCIR Team (Daniel Rogers, Kristen Walden, Jayson Shurgold, Jessica Eapen, Jerome Buenaventura, Tova Plashkes, Arlene Aspinall, Cynthia Morin, and Shannon Sproule); and the RHSCIR Network and all of the participating facilities: Vancouver General Hospital, G.F. Strong Rehabilitation Centre, Foothills Medical Centre, Royal Alexandra Hospital, University of Alberta Hospital, Glenrose Rehabilitation Hospital, Royal University Hospital, Saskatoon City Hospital, Winnipeg Health Sciences Centre, St. Michael's Hospital, Sunnybrook Health Sciences Centre, Toronto Western Hospital, Toronto Rehabilitation Institute - Lyndhurst Centre, Hamilton General Hospital, Hamilton Health Sciences - Regional Rehabilitation Centre, University Hospital, Victoria Hospital, Parkwood Hospital, The Ottawa Hospital - Civic Campus, The Ottawa Hospital Rehabilitation Centre, Hôpital de l'Enfant Jésus, Institut de réadaptation en déficience physique de Québec, Hôpital du Sacré-Coeur de Montréal, Centré de réadaptation Lucie-Bruneau, Institut de réadaptation Gingras-Lindsay-de-Montréal, QEII Health Sciences Centre, Nova Scotia Rehabilitation Centre, Saint John Regional Hospital, Stan Cassidy Centre for Rehabilitation, St. John's Health Sciences Centre, and Dr. Leonard A. Miller Rehabilitation Centre.

\section{Author Disclosure Statement}

This study was supported by financial contributions from the Rick Hansen Institute, the Ontario Neurotrauma Foundation, and the Government of Canada through Health Canada and Western Economic Diversification Canada.

\section{References}

1. Bowers, J., and Mould, G. (2001). Organisational implications of concentration orthopaedic services. Health Bull. (Raleigh) 59, 381-387.

2. Noonan, V.K., Soril, L., Atkins, D., Lewis, R., Santos, A., Fehlings, M.G., Burns, A.S., Singh, A., and Dvorak, M.F. (2012). The application 
of operations research methodologies to the delivery of care model for traumatic spinal cord injury: the access to care and timing project. J. Neurotrauma 29, 2272-2282.

3. Levin, S.R., Dittus, R., Aronsky, D., Weinger, M.B., Han, J., Boord, J., and France, D. (2008). Optimizing cardiology capacity to reduce emergency department boarding: a systems engineering approach. Am. Heart J. 156, 1202-1209.

4. McGirt, M.J., Parker, S.L., Asher, A.L., Norvell, D., Sherry, N., and Devin, C.J. (2014). Role of prospective registries in defining the value and effectiveness of spine care. Spine 39, S117-S128.

5. Noonan, V., Kwon, B., Soril, L., Fehlings, M., Hurlbert, R., Townson, A., Johnson, M., and Dvorak, M. (2012). The Rick Hansen Spinal Cord Injury Registry (RHSCIR): a national patient-registry. Spinal Cord 50, 22-27.

6. Santos, A., Gurling, J., Dvorak, M.F., Noonan, V.K., Fehlings, M.G., Burns, A.S., Lewis, R., Soril, L., Fallah, N., Street, J.T., Bélanger, L., Townson, A., Liang, L., and Atkins, D. (2013). Modeling the patient journey from injury to community reintegration for persons with acute traumatic spinal cord injury in a Canadian centre. PLoS One 8, e72552.

7. Graham, I.D., Logan, J., Harrison, M.B., Straus, S.E., Tetroe, J., Caswell, W., and Robinson, N. (2006). Lost in knowledge translation: time for a map? J. Contin. Educ. Health Prof. 26, 13-24.

8. Fehlings, M.G., Noonan, V.K., Atkins, D., Burns, A.S., Cheng, C.L., Singh, A., and Dvorak, M.F. (2017). Optimizing clinical decision making in acute spinal cord injury. J. Neurotrauma 2017 Jan 5. doi: 10.1089/neu.2016.4926 [Epub ahead of print]

9. Gruen, R.L., Gabbe, B.J., Stelfox, H.T., and Cameron, P.A. (2012). Indicators of the quality of trauma care and the performance of trauma systems. Br. J. Surg. 99, Suppl 1, 97-104.

10. Biering-Sørensen, F., Alai, S., Anderson, K., Charlifue, S., Chen, Y., DeVivo, M., Flanders, A.E., Jones, L., Kleitman, N., Lans, A., Noonan, V.K., Odenkirchen, J., Steeves, J., Tansey, K., Widerström-Noga, E., and Jakeman, L.B. (2015). Common data elements for spinal cord injury clinical research: a National Institute for Neurological Disorders and Stroke project. Spinal Cord 53, 265-277.

11. Maas, A.I., Menon, D.K., Lingsma, H.F., Pineda, J.A., Sandel, M.E., and Manley, G.T. (2012). Re-orientation of clinical research in traumatic brain injury: report of an international workshop on comparative effectiveness research. J. Neurotrauma 29, 32-46.

12. Kirshblum, S.C., Waring, W., Biering-Sorensen, F., Burns, S.P., Johansen, M., Schmidt-Read, M., Donovan, W., Graves, D., Jha, A., Jones, L., Mulcahey, M.J., and Krassioukov, A. (2011). Reference for the 2011 revision of the International Standards for Neurological Classification of Spinal Cord Injury. J. Spinal Cord Med. 34, 547-554.

13. Coleman, W.P., and Geisler, F.H. (2004). Injury severity as primary predictor of outcome in acute spinal cord injury: retrospective results from a large multicenter clinical trial. Spine J. 4, 373-378.

14. Fawcett, J.W., Curt, A., Steeves, J.D., Coleman, W.P., Tuszynski, M.H., Lammertse, D., Bartlett, P.F., Blight, A.R., Dietz, V., Ditunno, J., Dobkin, B.H., Havton, L., Ellaway, P.H., Fehlings, M.G., Privat, A., Grossman, R., Guest, J.D., Kleitman, N., Nakamura, M., Gaviria, M., and Short, D. (2007). Guidelines for the conduct of clinical trials for spinal cord injury as developed by the ICCP panel: spontaneous recovery after spinal cord injury and statistical power needed for therapeutic clinical trials. Spinal Cord 45, 190-205.

15. Geisler, F.H., Coleman, W.P., Grieco, G., and Poonian, D. (2001) Measurements and recovery patterns in a multicenter study of acute spinal cord injury. Spine 26, S68-S86.

16. Dvorak, M.F., Noonan, V.K., Fallah, N., Fisher, C.G., Rivers, C.S., Ahn, H., Tsai, E.C., Linassi, G., Christie, S.D., Attabib, N., Hurlbert, R.J., Fourney, D.R., Johnson, M.G., Fehlings, M.G., Drew, B., Bailey, C.S., Paquet, J., Parent, S., Townson, A., Ho, C., Craven, B.C., Gagnon, D., Tsui, D., Fox, R., Mac-Thiong, J.-M., and Kwon, B.K. (2014). Minimizing errors in acute traumatic spinal cord injury trials by acknowledging the heterogeneity of spinal cord anatomy and injury severity: an observational Canadian cohort analysis. J. Neurotrauma 31, 1540-1547.

17. Steeves, J.D., Lammertse, D., Curt, A., Fawcett, J.W., Tuszynski, M.H., Ditunno, J.F., Ellaway, P.H., Fehlings, M.G., Guest, J.D., Kleitman, N., Bartlett, P.F., Blight, A.R., Dietz, V., Dobkin, B.H., Grossman, R., Short, D., Nakamura, M., Coleman, W.P., Gaviria, M., and Privat, A. (2007). Guidelines for the conduct of clinical trials for spinal cord injury (SCI) as developed by the ICCP panel: clinical trial outcome measures. Spinal Cord 45, 206-221.
18. Dvorak, M., Noonan, V., Fallah, N., Öner, C., Fisher, C., Kwon, B.K., and Vaccaro, A. (2015). Mechanism of injury vs AO Spine Classification: is setting of injury better than morphology in predicting severity of SCI?, in: The 4th ISCoS and ASIA Joint Scientific Meeting. The International Spinal Cord Society: Montreal, QC.

19. Stroup, D.F., Berlin, J.A., Morton, S.C., Olkin, I., Williamson, G.D., Rennie, D., Moher, D., Becker, B.J., Sipe, T.A., and Thacker, S.B. (2000). Meta-analysis of observational studies in epidemiology: a proposal for reporting. JAMA 283, 2008-2012.

20. Moher, D., Liberati, A., Tetzlaff, J., Altman, D.G., The PRISMA Group. (2009). Preferred reporting items for systematic reviews and meta-analyses: the PRISMA statement. PLoS Med. 6, e1000097.

21. Teasdale, G., and Jennett, B. (1974). Assessment of coma and impaired consciousness. A practical scale. Lancet 304, 81-84.

22. Baker, S.P., O'Neill, B., Haddon, W., and Long, W.B. (1974). The injury severity score: a method for describing patients with multiple injuries and evaluating emergency care. J. Trauma 14, 187-196.

23. Grossman, R.G., Frankowski, R.F., Burau, K.D., Toups, E.G., Crommett, J.W., Johnson, M.M., Fehlings, M.G., Tator, C.H., Shaffrey, C.I., Harkema, S.J., Hodes, J.E., Aarabi, B., Rosner, M.K., Guest, J.D., and Harrop, J.S. (2012). Incidence and severity of acute complications after spinal cord injury. J. Neurosurg. Spine 17, 119-128.

24. Fletcher, D.J., Taddonio, R.F., Byrne, D.W., Wexler, L.M., Cayten, G., Nealon, S.M., and Carson, W. (1995). Incidence of acute care complictions in vertebral column fracture patients with and without spinal cord injury. Spine 20, 1136-1146.

25. DeVivo, M.J., Go, B.K., and Jackson, A.B. (2002). Overview of the national spinal cord injury statistical center database. J. Spinal Cord Med. 25, 335-338.

26. Hagen, E.M., Eide, G.E., Rekand, T., Gilhus, N.E., and Gronning, M. (2010). Traumatic spinal cord injury and concomitant brain injury: a cohort study. Acta Neurol. Scand. Suppl. 122, 51-57.

27. Oliver, M., Inaba, K., Tang, A., Branco, B.C., Barmparas, G., Schnüriger, B., Lustenberger, T., and Demetriades, D. (2012). The changing epidemiology of spinal trauma: A 13-year review from a Level I trauma centre. Injury 43, 1296-1300.

28. Noonan, V.K., Thorogood, N.P., Fingas, M., Batke, J., Bélanger, L., Kwon, B.K., and Dvorak, M.F. (2013). The validity of administrative data to classify patients with spinal column and cord injuries. J. Neurotrauma 30, 173-180.

29. Hagen, E.M., Rekand, T., Gilhus, N.E., and Gronning, M. (2009). Diagnostic coding accuracy for traumatic spinal cord injuries. Spinal Cord 47, 367-371.

30. Thurman, D.J., Burnett, C.L., Jeppson, L., Beaudoin, D.E., and Sniezek, J.E. (1994). Surveillance of spinal cord injuries in Utah, USA. Paraplegia 32, 665-669.

31. Noonan, V.K., Fingas, M., Farry, A., Baxter, D., Singh, A., Fehlings, M.G., and Dvorak, M.F. (2012). Incidence and prevalence of spinal cord injury in Canada: a national perspective. Neuroepidemiology 38 , 219-226.

32. Cripps, R., Lee, B.B., Wing, P., Weerts, E., Mackay, J., and Brown, D. (2011). A global map for traumatic spinal cord injury epidemiology: towards a living data repository for injury prevention. Spinal Cord 49, 493-501.

33. Atkins, D., Noonan, V.K., Santos, A., Lewis, R., Fehlings, M., Burns, A., and Dvorak, M. (2012). Secondary complications in SCI across the continuum: using operations research to predict the impact and optimize management strategies. Top. Spinal Cord Inj. Rehabil. 18, 57-66.

34. Street, J.T., Thorogood, N.P., Cheung, A., Noonan, V.K., Chen, J., Fisher, C.G., and Dvorak, M.F. (2013). Use of the Spine Adverse Events Severity System (SAVES) in patients with traumatic spinal cord injury. A comparison with institutional ICD-10 coding for the identification of acute care adverse events. Spinal Cord 51, 472-476.

35. Wardle, G., Wodchis, W.P., Laporte, A., Anderson, G.M., and Ross Baker, G. (2012). The sensitivity of adverse event cost estimates to diagnostic coding error. Health Serv. Res. 47, 984-1007.

36. Glennie, R.A., Noonan, V.K., Fallah, N., Park, S.E., Thorogood, N.P., Cheung, A., Fisher, C.G., Dvorak, M.F., and Street, J.T. (2014). Reliability of the spine adverse events severity system (SAVES) for individuals with traumatic spinal cord injury. Spinal Cord 52, 758763.

37. Spinal Cord Injury Research Evidence. (2017). Outcome Measures Toolkit. Available at: https://scireproject.com/outcome-measures/ toolkit/. Accessed April 3, 2017. 
38. Feeny, D. (2013). Health-related quality-of-life data should be regarded as a vital sign. J. Clin. Epidemiol. 66, 706-709.

39. Miller, D., Steele Gray, C., Kuluski, K., and Cott, C. (2015). Patientcentered care and patient-reported measures: let's look before we leap. Patient 8, 293-299.

40. Shi, J., Jia, L., Yuan, W., Shi, G., Ma, B., Wang, B., and Wu, J. (2010). Clinical classification of cauda equina syndrome for proper treatment: a retrospective analysis of 39 patients. Acta Orthop. 81, 391-395.

41. Watanabe, T., Vaccaro, A.R., Kumon, H., Welch, W.C., Rivas, D.A., and Chancellor, M.B. (1998). High incidence of coccult neurogenic bladder dysfunction in neurologically intact patients with thoracolumbar spinal injuries. J. Urol. 159, 965-968.

42. McCarthy, M.J., Aylott, C.E., Grevitt, M.P., Orth, F., and Hegarty, J. (2007). Cauda equina syndrome factors affecting long-term functional and sphincteric outcome. Neurol. Urodynamics 32, 207-216.

43. Podnar, S., Trsinar, B., and Vodusek, D.B. (2006). Bladder dysfunction in patients with cauda equina lesions. Neurourol. Urodyn. 25, 23-31.

44. Noreau, L., Cobb, J., Bélanger, L.M., Dvorak, M.F., Leblond, J., and Noonan, V.K. (2013). Development and assessment of a community follow-up questionnaire for the Rick Hansen Spinal Cord Injury Registry. Arch. Phys. Med. Rehabil. 94, 1753-1765.

45. Ahn, H., Singh, J., Nathens, A., MacDonald, R.D., Travers, A., Tallon, J., Fehlings, M.G., and Yee, A. (2011). Pre-hospital care management of a potential spinal cord injured patient: a systematic review of the literature and evidence-based guidelines. J. Neurotrauma 28, 1341-1361.

46. Consortium for Spinal Cord Medicine. (2008). Early acute management in adults with spinal cord injury: a clinical practice guideline for healthcare professionals. J. Spinal Cord Med. 31, 403-479.

47. Burns, A.S., Santos, A., Cheng, C.L., Chan, E., Fallah, N., Atkins, D., Dvorak, M.F., Ho, C., Ahn, H., Paquet, J., Kwon, B.K., and Noonan, V.K. (2016). Understanding length of stay following spinal cord injury: insights and limitations from the access to care and timing project. J. Neurotrauma 2017 Mar 29. doi: 10.1089/neu.2016.4935 [Epub ahead of print].

48. Canadian Institute for Health Information. (2017). Length of stay and length of stay efficiency of inpatient rehabilitation clients. Available at: http://indicatorlibrary.cihi.ca/pages/viewpage.action?pageId=11 14205. Accessed November 27, 2015.

49. Graham, J.E., Granger, C.V, Karmarkar, A.M., Deutsch, A., Niewczyk, P., Divita, M.A., and Ottenbacher, K.J. (2014). The Uniform Data System for Medical Rehabilitation: report of follow-up information on patients discharged from inpatient rehabilitation programs in 2002 2010. Am. J. Phys. Med. Rehabil. 93, 231-244.

50. Devivo, M.J. (2012). Epidemiology of traumatic spinal cord injury: trends and future implications. Spinal Cord 50, 365-372.

51. Ahn, H., Lewis, R., Santos, A., Cheng, C.L., Noonan, V.K., Dvorak, M.F., Singh, A., Linassi, A.G., Christie, S., Goytan, M., and Atkins, D. (2017). Forecasting financial resources for future traumatic spinal cord injury care using simulation modeling. J. Neurotrauma [Epub ahead of print.]

52. Dryden, D.M., Saunders, L.D., Jacobs, P., Schopflocher, D.P., Rowe, B.H., May, L.A., Yiannakoulias, N., Svenson, L.W., and Voaklander, D.C. (2005). Direct health care costs after traumatic spinal cord injury. J. Trauma 59, 443-449.

53. Munce, S., Wodchis, W., Guilcher, S., Couris, C., Verrier, M., Fung, K., Craven, B., and Jaglal, S. (2013). Direct costs of adult traumatic spinal cord injury in Ontario. Spinal Cord 51, 64-69.

54. Bradbury, C.L., Wodchis, W.P., Mikulis, D.J., Pano, E.G., Hitzig S.L., McGillivray, C.F., Ahmad, F.N., Craven, B.C., and Green, R.E. (2008). Traumatic brain injury in patients with traumatic spinal cord injury: clinical and economic consequences. Arch. Phys. Med. Rehabil. 89, S77-S84.

55. Hellsten, E.K., Hanbidge, M., Manos, A.N., Lewis, S.J., Massicotte, E.M., Fehlings, M.G., Coyte, P.C., and Rampersaud, Y.R. (2013). An economic evaluation of perioperative adverse events associated with spinal surgery. Spine J. 13, 44-53.

56. Whitehurst, D.G., and Mittmann, N. (2013). The value of health economics research in spinal cord injury. Spinal Cord 51, 586-587.

57. New, P.W., and Jackson, T. (2010). The costs and adverse events associated with hospitalization of patients with spinal cord injury in Victoria, Australia. Spine 35, 796-802.

58. Chan, B., McIntyre, A., Mittmann, N., Teasell, R.R., and Wolfe, D.L. (2014). Economic evaluation of spinal cord injury. In Eng, J.J., Tea- sell, R.W., Miller, W.C., Wolfe, D.L., Townson, A.F., Hsieh, J.T., Connolly, S.J., Noonen, V.K., Loh, E., McIntyre, A. (eds). Spinal Cord Injury Rehabilitation Evidence. Version 5.0: pps. 1-21.

59. Chan, E., Cheng, C.L., and Noonan, V.K. (2014). ACT Workshop proceedings. Available at: http://www.rickhanseninstitute.org/images/ stories/ACT_Proceedings/ACT_Proceedings_Final.pdf. Accessed March 28, 2017.

60. White, B.A. (2016). Health economics: agenda for SCI reseach in Canada. Available at: http://www.rickhanseninstitute.org/images/ stories/Article_PDFs/Health-Economics-report.pdf. Accessed March 28, 2017.

61. White, B.A., Dea, N., Street, J.T., Cheng, C.L., Rivers, C.S., Attabib, N., Kwon, B.K., Fisher, C.G., and Dvorak, M.F. (2017). The economic burden of urinary tract infection and pressure ulceration in acute traumatic spinal cord injury admissions: evidence for comparative economics and decision analytics from a matched case-control study. J. Neurotrauma [Epub ahead of print.]

62. Noonan, V.K., Chan, E., Santos, A., Soril, L., Lewis, R., Singh, A., Cheng, C.L., O'Connell, C., Truchon, C., Paquet, J., Christie, S., Ethans, K., Tsai, E., Ford, M., Drew, B., Linassi, A.G., Bailey, C.S., Fehlings, M.G., and RHSCIR Network. (2017). Traumatic spinal cord injury care in Canada: a survey of Canadian centres. J. Neurotrauma 2017 Apr 1. doi: 10.1089/neu.2016.4928 [Epub ahead of print].

63. Parent, S., Barchi, S., LeBreton, M., Casha, S., and Fehlings, M.G. (2011). The impact of specialized centers of care for spinal cord injury on length of stay, complications, and mortality: a systematic review of the literature. J. Neurotrauma 28, 1363-1370.

64. Accreditation Canada. (2017). Qmentum Program: Spinal Cord Injury Acute Services. Ottawa.

65. Accreditation Canada. (2017). Qmentum Program: Spinal Cord Injury Rehabilitation Services. Ottawa.

66. Biering-Sørensen, F., and Noonan, V. (2016). Standardization of data for clinical use and research in spinal cord injury. Brain Sci. 6, 29.

67. Brain and Spinal Injury Center UCSF. (2014). TRACK-TBI: transforming research and clinical knowledge in TBI. Available at: https:// tracktbi.ucsf.edu/. Cited April 4, 2017.

68. Maas, A., and Menon, D. (2017). CENTER-TBI. Available at: https:// www.center-tbi.eu/. Accessed April 4, 2017.

69. Yokobori, S., Zhang, Z., Moghieb, A., Mondello, S., Gajavelli, S., Dietrich, W.D., Bramlett, H., Hayes, R.L., Wang, M., Wang, K.K., and Bullock, M.R. (2015). Acute diagnostic biomarkers for spinal cord injury: review of the literature and preliminary research report. World Neurosurg. 83, 867-878.

70. Miyanji, F., Furlan, J.C., Aarabi, B., Arnold, P.M., and Fehlings, M.G. (2007). Acute cervical traumatic spinal cord injury: MR imaging findings correlated with neurologic outcome-prospective study with 100 consecutive patients. Radiology 243, 820-827.

71. Jones, J.G., Cen, S.Y., Lebel, R.M., Hsieh, P.C., and Law, M. (2013). Diffusion tensor imaging correlates with the clinical assessment of disease severity in cervical spondylotic myelopathy and predicts outcome following surgery. Am. J. Neuroradiol. 34, 471-478.

72. Noonan, V., Fallah, N., Bedi, M., Chan, E., Rivers, C., Street, J., Plashkes, T., and Dvorak, M. (2016). Developing a new index to predict mortality after spinal cord injury using machine learning techniques. Can. J. Surg 59, S45.

73. Tulsky, D.S., Jette, A.M., Kisala, P.A., Kalpakjian, C., Dijkers, M.P., Whiteneck, G., Ni, P., Kirshblum, S., Charlifue, S., Heinemann, A.W Forchheimer, M., Slavin, M.D., Houlihan, B., Tate, D.G., DysonHudson, T., Fyffe, D.G., Williams, S., Zanca, J., and Fyffe, D. (2012). Spinal cord injury-functional index: item banks to measure physical functioning in individuals with spinal cord injury. Arch. Phys. Med. Rehabil. 93, 1722-1732.

74. Tulsky, D.S., Kisala, P.A., Victorson, D., Tate, D.G., Heinemann, A.W., Charlifue, S., Kirshblum, S.C., Fyffe, D., Gershon, R., Spungen, A.M., Bombardier, C.H., Dyson-Hudson, T.A., Amtmann, D., Kalpakjian, C.Z., Choi, S.W., Jette, A.M., Forchheimer, M., and Cella, D. (2015). Overview of the spinal cord injury-Quality of life (SCI-QOL) measurement system. J. Spinal Cord Med. 38, 257-269.

75. LaVela, S.L., and Gallan, A. (2014). Evaluation and measurement of patient experience. Patient Exp. J. 1, 28-36.

76. Barrable, B., Thorogood, N., Noonan, V., Tomkinson, J., Joshi, P., Stephenson, K., Barclay, J., and Kovacs Burns, K. (2014). Model for bridging the translational "valleys of death" in spinal cord injury research. J. Healthc. Leadersh. 2014, 15-27. 
77. Rick Hansen Institute. (2016). Praxis 2016 Conference Report. Available at: http://www.rickhanseninstitute.org/images/doc/Praxis2016_ Conference_Report_November2016.pdf. Accessed March 28, 2017.

78. Tosetti, P., Hicks, R.R., Theriault, E., Phillips, A., Koroshetz, W., and Draghia-Akli, R. (2013). Toward an international initiative for traumatic brain injury research. J. Neurotrauma 30, 1211-1222.

79. Schuld, C., Wiese, J., Hug, A., Putz, C., van Hedel, H.J., Spiess, M.R., Weidner, N., Weidner EM-SCI Study Group, and Rupp, R. (2012). Computer implementation of the International Standards for Neurological Classification of Spinal Cord Injury for consistent and efficient derivation of its subscores including handling of data from not testable segments. J. Neurotrauma 29, 453-461.

80. Walden, K., Bélanger, L.M., Biering-Sørensen, F., Burns, S.P., Echeverria, E., Kirshblum, S., Marino, R.J., Noonan, V.K., Park, S.E., Reeves, R.K., Waring, W., and Dvorak, M.F. (2016). Development and validation of a computerized algorithm for International Standards for Neurological Classification of Spinal Cord Injury (ISNCSCI). Spinal Cord 54, 197-203.

81. Zariffa, J., Kramer, J.L., Jones, L.A., Lammertse, D.P., Curt, A., Steeves, J.D., and Steeves, J.D. (2012). Sacral sparing in SCI: beyond the S4-S5 and anorectal examination. Spine J. 12, 389-400.e3.

82. DeVivo, M.J., Biering-Sørensen, F., New, P., and Chen, Y. (2011) Standardization of data analysis and reporting of results from the International Spinal Cord Injury Core Data Set. Spinal Cord 49, 596599.

83. Taichman, D.B., Backus, J., Baethge, C., Bauchner, H., de Leeuw, P.W., Drazen, J.M., Fletcher, J., Frizelle, F.A., Groves, T., Haileamlak, A., James, A., Laine, C., Peiperl, L., Pinborg, A., Sahni, P., and $\mathrm{Wu}, \mathrm{S}$. (2016). Sharing clinical trial data-A proposal from the International Committee of Medical Journal Editors. N. Engl. J. Med. 374, 384-386.
84. One Mind. (2017). One Mind Portal. Available at: http://onemind.org/ Our-Solutions/One-Mind-Portal. Accessed April 3, 2017.

85. New, P.W., Baxter, D., Farry, A., and Noonan, V.K. (2015). Estimating the incidence and prevalence of traumatic spinal cord injury in Australia. Arch. Phys. Med. Rehabil. 96, 76-83.

86. Kalpakjian, C.Z., Scelza, W.M., Forchheimer, M.B., and Toussaint, L.L. (2007). Preliminary reliability and validity of a Spinal Cord Injury Secondary Conditions Scale. J. Spinal Cord Med. 30, 131-139.

87. Rehabilitation Outcome Measures. (2010). Rehabilitation Measures Database. Available at: http://www.rehabmeasures.org/. Accessed April 3, 2017.

88. Institut national d'excellence en santé et en services sociaux (INESSS). (2015). Trauma care continuum. Available at: http://fecst.inesss.qc.ca/ fileadmin/documents/Publications/Depliant_FECST_EN_2409015_ WEB.pdf. Accessed April 4, 2017.

89. Hosack, K. (2014). Spinal cord injury re-evaluations and follow-up care. Craig Hospital: Denver, CO.

90. World Health Organization. (2017.) Rehabilitation in health systems. Licence: CC BY-NC-SA 3.0 IGO. WHO: Geneva.

Address correspondence to: Marcel F. Dvorak, MD, MBA

Department of Orthopaedics University of British Columbia 6180-818 West 10th Avenue Vancouver, British Columbia V5Z 1 M9 Canada

E-mail: marcel.dvorak@ubc.ca 